A N N A L E S Annales de Bretagne et des Pays de l'Ouest

\title{
Initiateurs et entrepreneurs culturels du tourisme
}

\section{François Ploux}

\section{OpenEdition}

\section{Journals}

Édition électronique

URL : http://journals.openedition.org/abpo/2445

DOI : $10.4000 / a b p o .2445$

ISBN : 978-2-7535-2129-2

ISSN : 2108-6443

\section{Éditeur}

Presses universitaires de Rennes

Édition imprimée

Date de publication : 30 juin 2012

Pagination : 221-223

ISBN : 978-2-7535-2127-8

ISSN : 0399-0826

Référence électronique

François Ploux, «Initiateurs et entrepreneurs culturels du tourisme ». Annales de Bretagne et des Pays de I'Ouest [En ligne], 119-2 | 2012, mis en ligne le 30 juin 2012, consulté le 09 juillet 2020. URL : http:// journals.openedition.org/abpo/2445

Ce document a été généré automatiquement le 9 juillet 2020

(c) Presses universitaires de Rennes 


\title{
Initiateurs et entrepreneurs culturels du tourisme
}

\author{
François Ploux
}

\section{RÉFÉRENCE}

Andrieux, Jean-Yves et Harismendy, Patrick (dir.), Initiateurs et entrepreneurs culturels $d u$ tourisme (1850-1950), Rennes, PUR, 2011, 302 p. (ISBN 978-2-7535-1363-1).

1 Entre 1850 et 1950, l'essor du tourisme en France s'est accompagné d'un immense travail de caractérisation des territoires que l'amélioration du système des transports rendait davantage accessibles aux vacanciers. Les promoteurs du tourisme, souvent issus du monde de l'érudition provinciale, élaborèrent un savoir destiné à rendre plus aisément identifiables, et surtout plus attractifs, des lieux dont on voulait consolider la vocation touristique.

2 Sous couvert d'une mise en valeur des patrimoines vernaculaires (monuments, paysages, traditions...), il s'agissait en fait d'assigner une identité particulière à un territoire donné. À la limite, comme le montre Saskia Cousin à propos de l'invention du " Pays lochois », ce travail d'inventaire des cultures et patrimoines locaux visait à faire advenir à la conscience collective un territoire qui, jusqu'alors, n'avait aucune espèce d'existence objective ou subjective.

3 C'est cette question de l'articulation entre activités culturelles de production d'un savoir local, « mise en tourisme » (p. 276) des territoires et développement régional qui constitue le fil conducteur de l'ouvrage codirigé par Patrick Harismendy et Jean-Yves Andrieux. Les dix-neuf études de cas présentées dans ce recueil richement illustré permettent de dégager certaines modalités de cette invention des traditions touristiques.

4 Concernant les hommes d'abord. Cette première génération de promoteurs du tourisme était constituée d'érudits polygraphes. Si les antiquaires du premier xix ${ }^{e}$ siècle contribuèrent directement à l'élaboration des stéréotypes régionaux (comme le montre 
par exemple François Guillet à propos de la Normandie), après 1880 les activités de promotion culturelle furent davantage, ou plus explicitement, associées à la défense des intérêts économiques locaux. L'ouvrage propose une galerie de portraits de ces entrepreneurs du tourisme, notables de modeste envergure, mais suffisamment fortunés pour pouvoir consacrer leur vie à exalter le "génie " et les beautés de leur petite patrie. Le Briochin Octave-Louis Aubert fut une figure emblématique de cette génération. Né à Paris, breton "d'adoption" par conséquent, il vécut et mourut à Saint-Brieuc. Il fut simultanément publiciste, éditeur, bibliophile, historien, conseiller municipal et membre actif de la scène culturelle bretonne. Aubert est très représentatif d'une génération qui entendait articuler le développement touristique régional et la mise en valeur culturelle. Il consacra toute son énergie à célébrer l'« âme bretonne " (voire, comme en décembre 1942, «les qualités et les vertus de la race bretonne »). Parce qu'il était adepte du régionalisme politique de Jean Charles-Brun, sa critique du centralisme n'alla jamais jusqu'à la remise en cause de l'appartenance de la Bretagne à la France. La création de La Bretagne touristique en 1922 fut une étape importante de l'action d'Aubert en faveur du développement touristique (Gilles Willems). La revue comportait une rubrique consacrée aux formes savantes d'expression musicale, ce qui révèle une conception assez ouverte de la " culture bretonne » (Marie-Claire Mussat).

On trouvera dans le recueil toute une série de portraits de ces acteurs de la «mise en tourisme" des territoires. Annie Bleton-Ruget s'est intéressée à Gabriel Jeanton (1881-1943), magistrat bourguignon, auteur de travaux sur le folklore du Mâconnais, qui milita en faveur d'une renaissance des traditions populaires locales. En réalité Jeanton inventa un folklore "de marketing " (p. 52), destiné à valoriser la Bourgogne viticole. Raymond Ritter (1894-1974), que présente Estelle Delahaye, était avocat de profession, mais par ailleurs historien, archéologue et collectionneur. Il consacra beaucoup de temps et d'énergie à la sauvegarde du patrimoine monumental pyrénéen, et s'illustra en outre dans la publication de guides à l'usage des touristes. Saskia Cousin s'attache quant à elle à Jacques-Marie Rougié (1873-1956), fondateur du syndicat d'initiative de Loches, d'un musée du terroir, auteur d'un guide, et véritable inventeur - à des fins de promotion touristique - du «Pays lochois». Vincent Biot montre qu'Edouard-Alfred Martel fut, dans les années 1880, le véritable découvreur des Grands Causses, territoire durement frappé par le déclin des industries rurales, mais reconverti en destination touristique. Médecin militaire, et archéologue amateur en délicatesse avec l'archéologie officielle, Louis Carton joua néanmoins un rôle essentiel dans la mise en tourisme du site de Carthage (Myriam Bacha). Hind Oualid El Alaoui étudie le rôle de Victor Morin dans la patrimonialisation du vieux Montréal.

6 Un peu différente est la personnalité de l'abbé Gillard (1901-1979). Marcel Calvez expose la contribution décisive de ce prêtre à l'élaboration d'une topographie légendaire de Brocéliande centrée sur l'église de Tréhorenteuc. Au début des années 1940, l'abbé Gillard entreprit de restaurer cet édifice délabré, qu'il décora d'un vitrail de la Table Ronde. Sous son impulsion (il édita des brochures, fit office de guide touristique, et fut dans les années 1960 co-fondateur d'un syndicat d'initiative), la petite paroisse de Tréhorenteuc devint le lieu central à partir duquel s'organisait l'exploration de Brocéliande.

7 Deux chapitres passionnants abordent la question des emblèmes patrimoniaux. Le travail de Pascal Aumasson, Gwénaël Le Berre et Genevière Le Berre sur l'origine du kabig est exemplaire. L'enquête retrace avec beaucoup de minutie la destinée de ce 
vêtement, dont on peut dire qu'elle est indissociable du développement du tourisme. À l'origine vêtement de travail des goémoniers du Pays pagan, dans le Finistère, le kabig fut adopté par les vacanciers, avant d'être érigé par un Pierre-Yves Creston en « costume national » (p. 204) d'une jeunesse bretonne invitée à résister à la pénétration de la mode citadine. Tout ceci ne put évidemment s'accomplir sans de multiples remodelages, qui constituent autant de distorsions par rapport au référent originaire : le kabig du commerce n'avait pas grand chose à voir avec celui des ramasseurs de varech. On ne peut s'empêcher de sourire en apprenant qu'Herry Caouissin, « conseiller ethnologique " du film Un recteur de l'île de Sein, suggéra au réalisateur de vêtir les comédiens de kabigs que nul pêcheur sénan n'avait jamais portés.

8 Vincent Guigueno étudie de son côté comment, à la fin du xix ${ }^{e}$ siècle, la presse populaire érigea le phare en icône d'une Bretagne identifiée à son étroite frange littorale. En l'espace de quelques décennies, le phare devint un symbole majeur de la Bretagne, alors même qu'il existe ailleurs - sur les côtes anglaises par exemple - des milliers d'édifices semblables, mais qui ne font pas l'objet de la même obsession patrimoniale. Pourtant si l'image du phare est véritablement proliférante, le nombre de visiteurs demeure faible.

Un troisième axe du recueil concerne les institutions locales qui relayèrent l'action des entrepreneurs de tourisme. Nabila Oulebsir étudie l'action des syndicats d'initiative nord-africains dans le développement du tourisme patrimonial en Méditerranée. Julie Manfredi s'intéresse elle aussi aux syndicats d'initiative, mais cette fois à propos de la promotion du tourisme à Hyères. Enfin Fabrice Marzin retrace l'histoire du Comité d'études et de liaison des intérêts bretons (le CÉLIB), au sein duquel Octave-Louis Aubert joua un rôle central jusqu'à sa mort.

À l'heure où la promotion des produits bretons ou du tourisme en Bretagne ne cesse de faire référence à une "identité » régionale dont on semble postuler qu'elle pourrait exister en dehors des discours et des représentations, cet ouvrage a le mérite de rappeler que l'élaboration de ce type de fiction recouvre des enjeux bien réels. Et sert des intérêts parfaitement objectivables. 